\title{
The analysis of the limit loads of selected cracked welded plates - the undermatching issues
}

\author{
MARCIN GRABA*
}

Dr inż. Marcin Graba, mgraba@tu.kielce.pl, https://orcid.org/0000-0001-7520-8330 - Faculty of Mechatronics and Mechanical

Engineering, Kielce University of Technology, Kielce, Poland

The paper presents the results of numerical verification of the limit loads of DEN(T) welded plates, referring to the formulas proposed in the FITNET procedures. The analysis concerned on selected cases of geometry plate, and the mismatch of the weld and base material was limited to the cases of undermatching.

KEYWORDS: limit loads, welded plate, DEN(T) plate, undermatching, plastic zone

Welded joints have been the subject of scientific and engineering considerations for many years. There were many publications, as well as principles of calculating welded joints in normative documents. This applies to both the national and European scientific community.

In 2004, a group of researchers-engineers operating under the auspices of the European Union presented a document known as SINTAP procedures [1]. In 2006, it was published under the name FITNET [2]. The European Commission recommends using this publication to assess the strength of various structural components containing defects, which is reflected in the textbook [3].

In addition to considerations on structural elements made of homogeneous material, FITNET procedures [2, 3] present recommendations on how to estimate the limit loads - limit load capacity of welded structural elements, in which defects appeared.

The authors of the procedures [2] presented comprehensive considerations regarding expanded plates with variously located defects, cracked bending beams and even welded pipes, in which defects appeared. When considering welded structures, the authors of procedures [2] ignore the width of the heat affected zone (SWC), and locate the crack in the center of the weld, on the border of the weld and the base material, or consider a welded connection [3].

One of the considered geometries of welded plates is a plate with double-sided crack, marked as DEN(T) - fig. 1 - in which the defect is located in the center of the weld. Geometry of this plate can be fully characterized by the following parameters:

- $a$ - defect length;

- $2 h$ - total width of the weld;

- $2 W$ - total width of the plate;

- $B$ - plate thickness;

- $2 L$ - total length of the plate;

- $R_{e}^{b}$ - yield strength for base material (base);

- $R_{e}^{w}$ - yield stress for the weld;

- $\quad M$ - mismatch factor of the weld material and base material calculated as $M=R_{e} w / R_{e} b$;

- $\psi$ - coefficient being a function of geometrical dimensions of the plate calculated as $\psi=(W-a) / h$ [3]. 


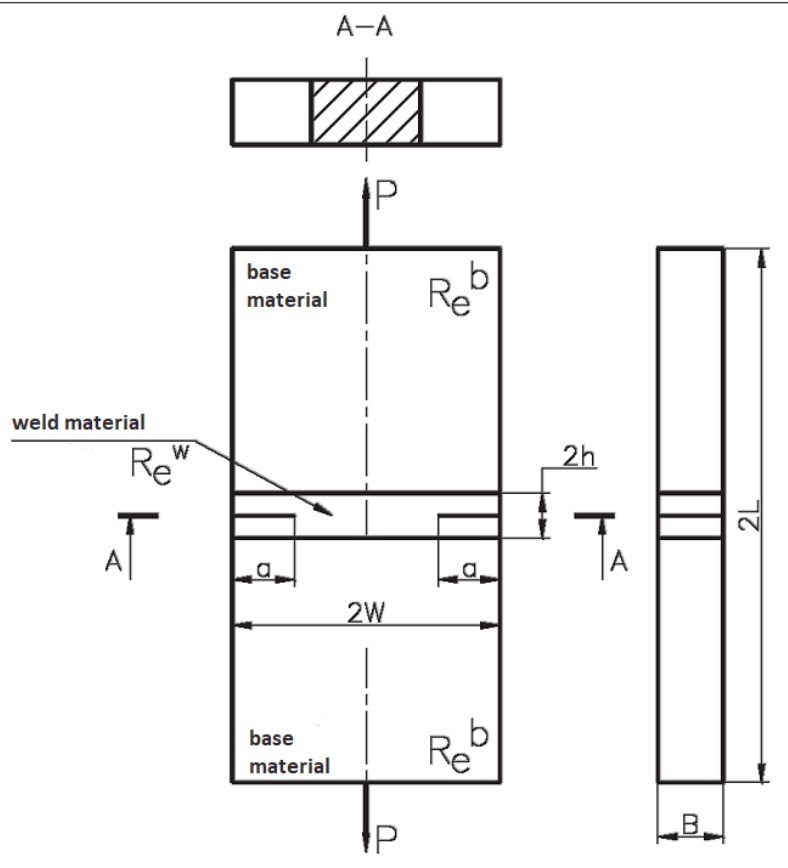

Fig. 1. Welded plate with a two-sided crack in the middle of the weld

Based on geometrical dimensions of the plate, the material characteristics of the base and weld and the boundary load capacity $P_{0}$ of such a structural element for the case of dominance of flat deformation (PSO), it can be estimated in accordance with the solution given in EPRI procedures [4]:

$$
P_{0}=(0,72+1,82 \mathrm{~b} / W) \cdot \sigma_{0} \cdot W
$$

where: $\sigma_{0}$ - yield stress, which is assumed to be the lower of the yield strength of the base material $R_{e}^{b}$ and the weld material $R_{e}^{w}$.

However, according to the authors of FITNET procedures [3], this approach is not appropriate. On the basis of a number of considerations, they proposed slightly different scheme for estimating the limit load capacity, which takes into account the mismatch factor of the base material and weld material, as well as the characteristic dimensions of the weld. They provided these formulas both for the case when the weld material is stronger than the base material $(M>1)$ - overmatching, and for the issue considered in this paper, when the weld material is weaker than the base material $(M<1)$ - undermatching [1-2]. Due to their considerable spread, they will not be quoted here; they can be found in [1-3].

\section{FEM modeling principles}

The ADINA package was used in the FEM (Finite Element Method) numerical calculations [5, 6]. Due to the existing symmetry axes, only the fourth part of the welded DEN(T) plate was modeled.

In accordance with the recommendations of the FITNET procedures [2], the plate was divided into two parts: the part being a weld (characterized by mechanical properties of the weld material) and the part modeled using base material.

An elastic-perfectly plastic model of the material, both weld and base material, was assumed, setting Young's modulus $E=206 \mathrm{GPa}$, Poisson's ratio $v=0.3$, yield strength of base material $R_{e}^{b}=275 \mathrm{MPa}$, where the yield strength of the weld material was determined from the relation $R_{e}^{w}=M \times R_{e}^{b}$, assuming different values of the mismatch factor of the weld material and the parent material $M=\{0.25 ; 0.30 ; 0.35 ; 0.50 ; 0.65 ; 0.75 ; 0.80 ; 0.85$; $0.90 ; 0.95\}$.

The choice of yield stress is not accidental - the value used in the numerical calculations corresponds to the material characteristics of S275J steel, which is used in welded constructions, in machine construction and steel construction, as well as for the manufacture of lightly loaded levers, mandrels, axles and shafts. Calculations assumed a fixed panel width $W=40 \mathrm{~mm}$, length $L=80 \mathrm{~mm}$, relative constant crack length $a / W=0.50$ (considerations for very short, short and long gaps will be published soon) and different joint width $H=\{05$; $1.0 ; 1.5 ; 2.0 ; 2.5 ; 3.0\}$. 
The crack tip was modeled in the form of a semicircle with a radius $r_{w}=1 \mu \mathrm{m}$, which was divided in circumferential direction into 24 parts. The apical region with a radius of $250 \mu \mathrm{m}$ was radially divided into 18 finite elements (FE), the smallest (located at the crack tip) was 20 times smaller than the last in this area.

The entire FEM model was completed with a total of 12,716 nine-node 2D PLANE STRAIN SOLID type FE (with nine numerical integration points, FEs with interpolation formulated as mixed), which means that 51267 nodes were used in this model. The external load was applied to the upper edge of the plate in a form of linear increase during displacement.

\section{Selected results of FEM calculations}

State of reaching the limit load by the plate was assumed to be the moment when the entire uncracked section of the specimen became plasticized - this assessment was carried out on the basis of an analysis increasing with the external load of the plastic zone. Specimen fragments, in which the effective stress calculated according to the Huber-Mises-Hencky hypothesis reached the value equal to or greater than the yield strength - respectively weld material or base material, depending on the location - were adopted as the plasticized area.


Fig. 2. Impact of the mismatch factor on the distribution of the plastic zone when the DEN(T) welded plate reaches the ultimate limit load (joint width $2 H=2 \mathrm{~mm}$ ): a) $M=0.25$; b) $M=0.50$; c) $M=0.75$; d) $M$ $=0.90$

Fig. 2 presents examples of the distribution of plastic zones recorded during numerical calculations for welded plates with a double edge crack, weld width $2 \mathrm{H}=2 \mathrm{~mm}$.

In the case of welded plates, which are characterized by a significant mismatch between the weld material and the base material, at the time of achieving full plasticization of the uncracked specimen section, the plastic zone is observed only in the weld area (fig. 2a). The weld slightly plasticizes when the mismatch coefficient is greater than or equal to $M \geq 0.75$ - the plastic zone, which causes plasticization of the non-cracked section of the specimen, develops from the tip of the crack along a line inclined to the horizontal axis of the specimen at an angle of less than $30^{\circ}$ (fig. 2c, d).

Numerically estimated values of the ultimate limit load are illustrated with two Figures. Fig. 3 presents the influence of the weld width with variable mismatch between the base material and the weld material, while in fig. 4 - the inverse relationship. 
The analysis shows that in the considered range of mismatch coefficients $M$, the width of the weld hardly affects the level of the boundary load at the same level of the mismatch factor $M$. The maximum percentage differences in the values of limit loads between a $2 H=1 \mathrm{~mm}$ and $2 H=2 \mathrm{~mm}$ wide joint $\mathrm{mm}$ are about $0.7 \%$ (with the same value of the mismatch coefficient of the base material and weld material), and the average difference for the entire data set is about $0.04 \%$. If the limit load values for plates with a $2 H=1 \mathrm{~mm}$ and $6 \mathrm{~mm}$ joint are compared, the maximum differences at the same value of the mismatch factor $M$ are $4.6 \%$, and the average difference for the whole spectrum of mismatch coefficients is about $2.3 \%$.

In the considered range of weld width, in the case of plane strain state domination and undermatching situations (mismatch coefficient of the base material and base material $M<1$ ), an evident relationship between the limit load capacity (limit load) and the mismatch factor $M$ (fig. 4) is observed. The lower the value of the mismatch factor - the greater the difference in the yield strength of the weld material and the base material the lower the ultimate load capacity.

For welded plates, in which the mismatch factor of the weld material and the parent material $M=0.90$, the limit load drops by a maximum of $1 \%$ compared to the limit load value estimated for $M=0.95$ (the average decrease is approximately $0.12 \%$ for the whole range of crack width considered). Referring successive limit load values for subsequent plates with different coefficient of mismatch between the base material and the weld material to the limit load capacity for $M=0.95$, the following relative differences are obtained: for $M=\{0.85$; $0.80 ; 0.75 ; 0.65 ; 0.50 ; 0.35 ; 0.30 ; 0.25\}$ maximum differences are respectively $\{1.12 \% ; 1.31 \% ; 1.23 \% ; 2.18 \%$; $5.76 \% ; 32.54 \% ; 41.97 \% ; 51.93 \%\}$, mean differences are respectively $\{0.51 \% ; 0.27 \% ; 0.77 \% ; 1.13 \% ; 3.81 \%$; $31.38 \% ; 41.00 \% ; 50.81 \%\}$.

It can be seen that the effect of the mismatch coefficient of the weld material and the base material on the ultimate bearing capacity (limit load) of welded plates with a crack located in the center of the weld is visible when the value of the mismatch factor $\mathrm{M}<0.65$.

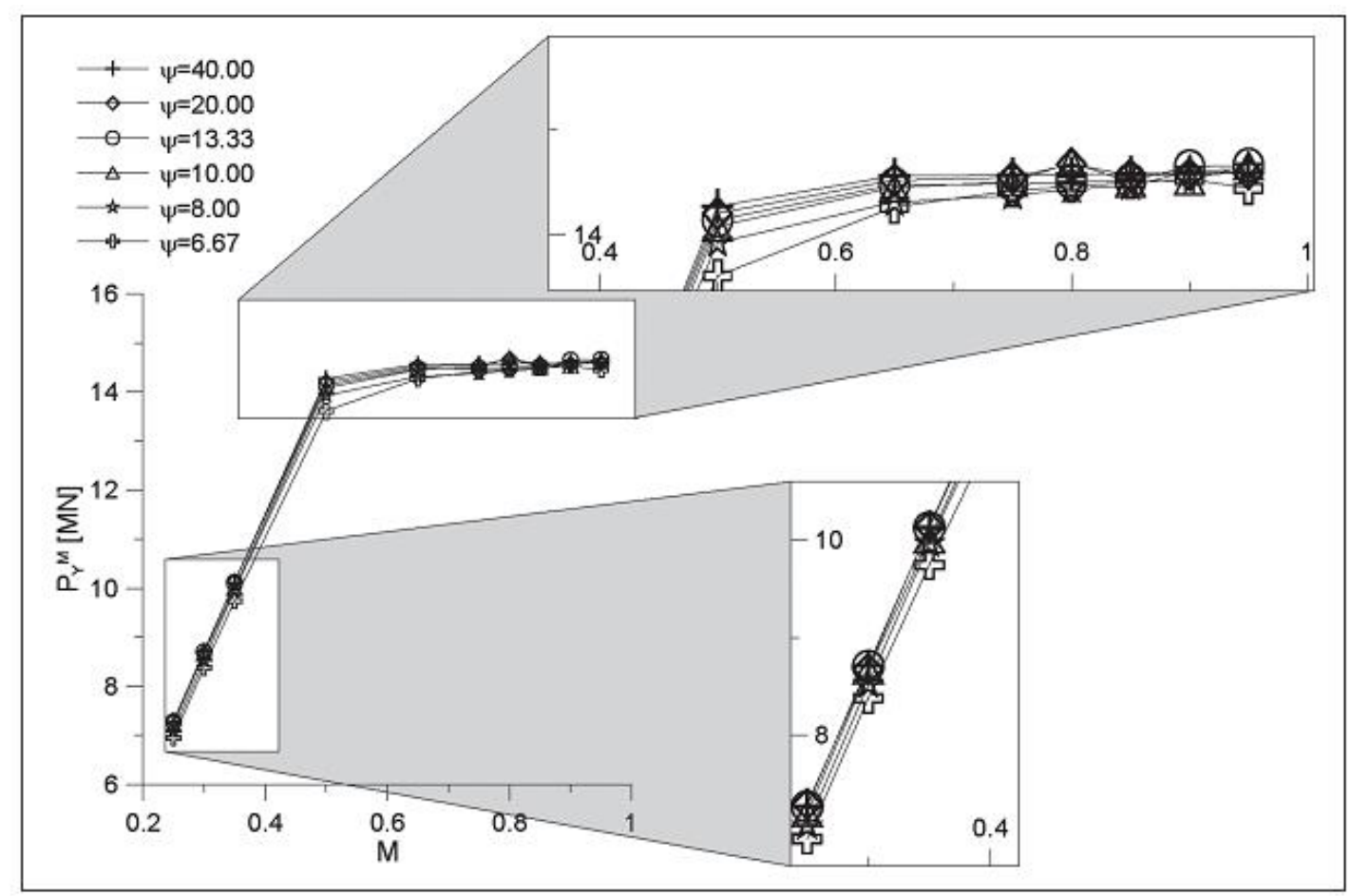

Fig. 3. Impact of the weld width on the limit load capacity of the welded DEN(T) plate with a crack in the weld (dominance of plane strain state, $W=40 \mathrm{~mm}, a / W=0.50, R_{e}^{b}=275 \mathrm{MPa}$ ) 


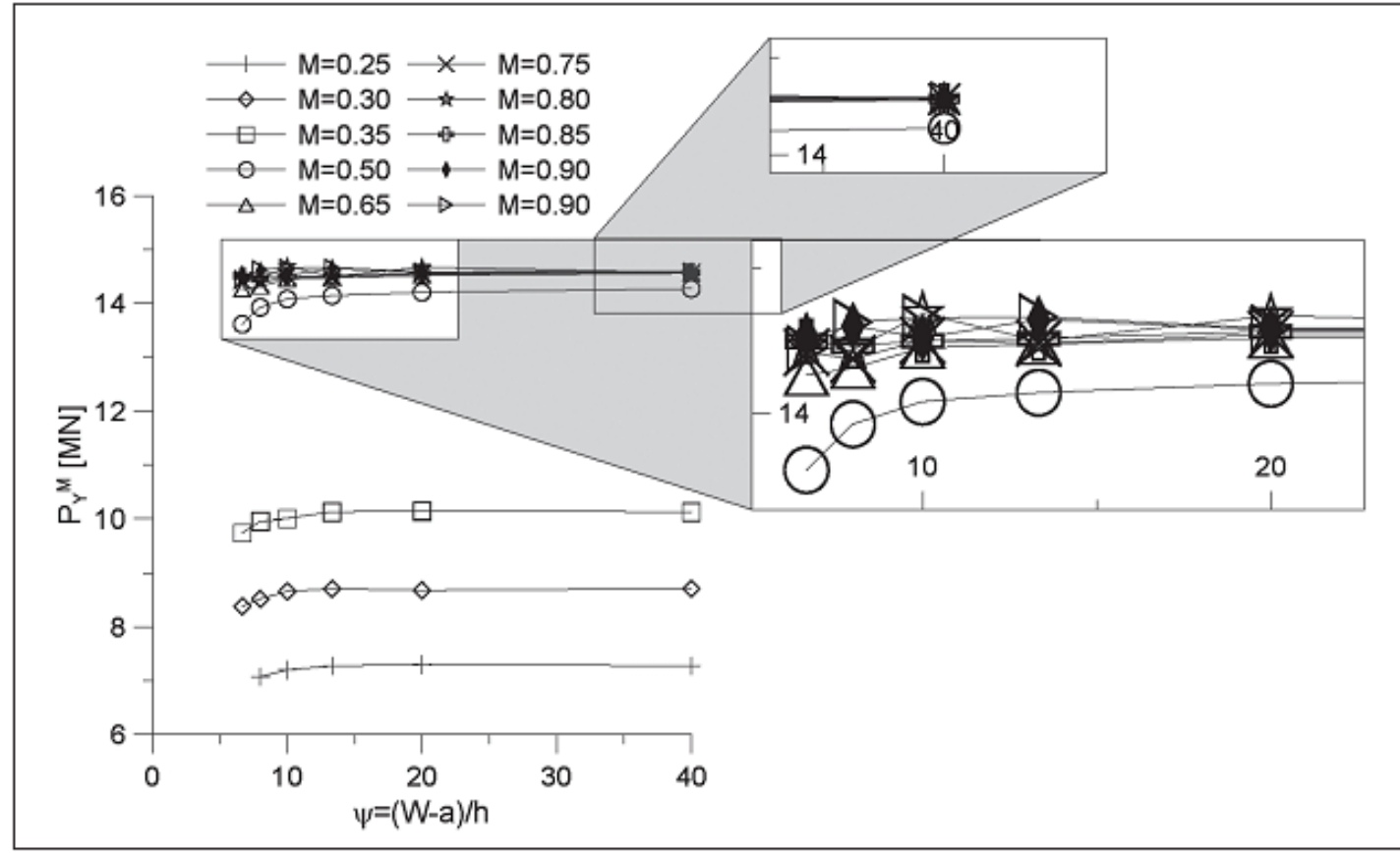

Fig. 4. Impact of the mismatch factor $M$ on the level of ultimate load capacity of the welded DEN(T) plate with a crack in the weld (dominance of plane strain state, $W=40 \mathrm{~mm}, a / W=0.50, R_{e}^{b}=275 \mathrm{MPa}$ )

Numerically estimated limit load values were compared with the values obtained on the basis of procedures [2] and [4] (fig. 5). The limit load determined according to FITNET procedures turns out to be a little conservative approach - the results are overstated, which can lead to the destruction of the structural element. Presented results should be verified experimentally, however, it should be remembered that the real structural element is made of elastic-plastic material with a certain level of strengthening, and in theoretical and numerical considerations, the ultimate limit load is determined assuming elastically-perfectly plastic material (without hardening). Possible experimental verification would probably confirm the conservatism of each of these solutions and depending on the needs and possibilities, one of these solutions would be considered appropriate.

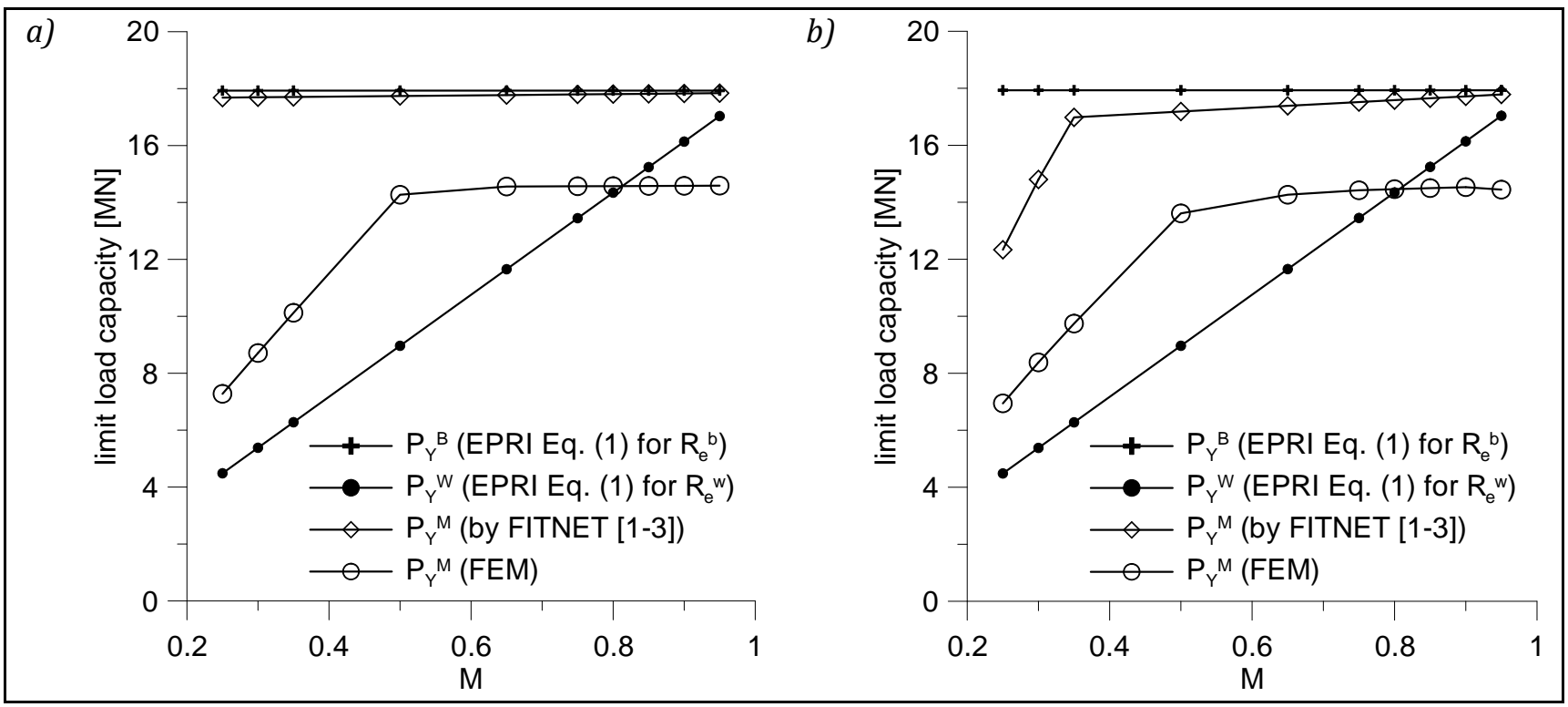

Fig. 5. Comparison of the results of the numerical limit load calculations for welded DEN(T) plates with a gap in the weld center with the solutions of procedures [2] and [4]: a) $\psi=40 ; 2 \mathrm{H}=1 \mathrm{~mm} ; b$ ) $\psi=6.67$; 


\section{Summary}

Results of numerical verification of the limit load capacity of welded plates with a double edge crack in tension are presented, referring to the formulas proposed in the FITNET procedures [2]. The analysis concerned selected plate geometries, and the mismatch of the weld material and base material was limited to undermatching cases - when the weld material is weaker than the base material of the plate.

The principles of developing the FEM model are briefly presented, selected results of numerical calculations are presented, which are illustrated by the distribution of developing plastic zones. As shown, the distribution of the plastic zone depends on the mismatch of base and weld material and - to a lesser extent - the width of the weld - especially when the weld material is much weaker than the base one. The limit load capacity depends not only on the yield strength of both materials, but also on the level of their mismatch and joint width, but to a relatively small extent.

The paper was carried out as part of the statutory work at the Faculty of Mechatronics and Mechanical Engineering at the Kielce University of Technology, No. 01.0.09.00/2.01.01.01.0027 MNSP.MKTM.17.002.

\section{REFERENCES}

[1] SINTAP Procedure: "Structural Integrity Assessment Procedures for European Industry. Final Procedure". Brite-Euram Project No BE95-1426. Rotherham: British Steel, 1999.

[2] Kocak M., Webster S., Janosch J.J., Ainsworth R.A., Koers R. "FITNET Report, (European Fitness-for-service Network)". Contract No. G1RT-CT-2001-05071, 2006.

[3] Neimitz A., Dzioba I., Graba M., Okrajni J. "The assessment of the strength and safety of the operation high temperature components containing crack". Kielce: Kielce University of Technology Publishing House, 2008.

[4] Kumar V., German M.D., Shih C.F. "An engineering approach for elastic-plastic fracture analysis". Palo Alto, CA: Electric Power Research Institute, Inc., EPRI Report NP-1931, 1981.

[5] ADINA 8.7.3: ADINA: "Theory and Modeling Guide - Volume I: ADINA". Report ARD 08-7, ADINA R\&D, Inc., 2008.

[6] ADINA 8.7.3: "ADINA: User Interface Command Reference Manual - Volume I: ADINA Solids \& Structures Model Definition". Report ARD 08-6, ADINA R\&D, Inc., 2008. 